\title{
An Empirical Investigation of a New Measure to Assess Abrasive Personality Disorder Traits
}

\author{
Frederick L. Coolidge, Ivan Valenzuela, Daniel L. Segal, Leilani Feliciano \\ Psychology Department, University of Colorado, Colorado Springs, USA \\ Email: fcoolidg@uccs.edu
}

How to cite this paper: Coolidge, F. L., Valenzuela, I., Segal, D. L., \& Feliciano, L. (2018). An Empirical Investigation of a New Measure to Assess Abrasive Personality Disorder Traits. Psychology, 9, 114-123. https://doi.org/10.4236/psych.2018.91008

Received: November 8, 2017

Accepted: January 22, 2018

Published: January 25, 2018

Copyright $\odot 2018$ by authors and Scientific Research Publishing Inc. This work is licensed under the Creative Commons Attribution International License (CC BY 4.0).

http://creativecommons.org/licenses/by/4.0/

\section{cc) (i) Open Access}

\begin{abstract}
The psychometric properties of a new measure, the 33-item Abrasive Personality Traits scale, were investigated. College students $(N=84)$ completed the scale about someone they perceived as abrasive and an additional 75 college students completed it about someone who they did not consider abrasive. The scale had good internal reliability and acceptable test-retest reliability. Abrasive people were rated significantly higher on the scale than non-abrasive people (large effect size). The scale was also strongly and significantly correlated with the Narcissistic, Paranoid, Sadistic, Antisocial, and Passive-Aggressive personality disorders on the Coolidge Axis II Inventory. The results preliminarily demonstrate that abrasiveness may constitute a psychometrically reliable personality cluster, warranting further investigation.
\end{abstract}

\section{Keywords}

Abrasive Personality Traits, Abrasive Personality Traits (APT) Scale Assessment, Personality Disorder, Coolidge Axis II Inventory, CATI

\section{Introduction}

\subsection{An Empirical Investigation of a New Measure to Assess Abrasive Personality Disorder Traits}

The origins of people who are difficult to deal with perhaps stretch back to the beginnings of the genus Homo, when human groups' size increased dramatically (e.g., Coolidge \& Wynn, 2018). Abrasiveness as a dysfunctional personality trait was described around 319 BC, by Theophrastus, a student of both Plato and Aristotle. In his short book, Characters (edited and translated by Rusten, Cunningham, \& Knox, 1993) Theophrastus described 30 personality types that he had observed in Greek life in Athens. Interestingly, he described six characters in 
particular, which may have heralded modern conceptions of abrasive people: the "dissembling type" was described as one who denigrates other people's thoughts and actions, and who is misleading, hypocritical, and two-faced; the "shameless" type was described as saying and doing "unseemly" things and willing to do any job and do whatever it took to get attention; the "grouchy" character was said to be extremely verbally hostile socially in order to hide personal short-comings; the "griper" character was described as being perpetually unhappy; "arrogant" characters were described as thinking that they were better than others; and the "slander" character was described as having a tendency toward derogatory and slanderous comments about others.

\subsection{A More Recent History}

Schneider (1958) and later Millon and Birket-Smith (1998) described an abrasive psychopath, as one who had little social conscience, exploited others, had narcissistic traits, was contentious, caustic, quarrelsome, corrosive, and had sudden emergences of hostility. All of these traits, Millon and his colleague postulated, were accompanied by a lack of remorse. They also claimed the abrasive psychopath found everyone as a target for nagging and assaulting, and he proposed that they discharged their inner irritabilities on other people as a result of his or her essential abrasiveness and antagonistic features. They also stated that the abrasive psychopath exhibited traits associated with the negativistic (passive-aggressive) and paranoid personality disorders. Their hostile nature, he surmised, was most often unprovoked and that they might retaliate in the presence of perceived threats.

\subsection{Abrasiveness as a Personality Disorder}

Litvak (1994) may have been the first to propose that an individual with abrasive personality traits should be considered a distinct personality disorder and not just a subtype of psychopathy. Litvak argued that an abrasive personality disorder diagnosis shares features with some of the then current diagnosable Axis II personality disorders in Diagnostic and Statistical Manual of Mental Disorders (DSM-III-R; American Psychiatric Association), yet he argued that the abrasive personality is unique in particular ways, and thus, distinct from the others. Litvak described the abrasive individual as overbearing, manipulative, and invalidating of other people's self-worth, which may lead to the tendency to diminish others for the purpose of undermining their self-esteem. Litvak also proposed a list of 12 criteria for diagnosis of the abrasive personality disorder and they are as follows:

(1) discourteous behavior; (2) overbearing, dominating, authoritarian, and inflexible behavior; (3) a compulsive tendency to control others and situations; (4) power-driven, often with a contempt for authority, yet craving approval from

others; (5) over-aggressive and intimidating of others (which may also be referred to in more recent terms as bullying); (6) need to be right with others; (7) 
projection of mistakes and blame upon others; (8) need to be the top-dog; not easily submitting to others; (9) tendency to break rules, making up rules to fill their own needs; (10) manipulative, setting "double-binds", building others up and then "cutting them down"; (11) hostile aggressive, using punishment or retribution as means of control or aggression; (12) building relationships and then cutting them off.

Litvak's (1994) paper was not an empirical investigation, yet he did call for "research in this virgin territory" (p. 7). Thus, the present study answers Litvak's call, attempting to create a reliable and valid scale that will measure abrasiveness accurately. Although Litvak's argument has been numerously cited in more recent research associated with personality types, there have been no further attempts to validate a diagnosis of abrasive personality disorder. There have been descriptions of abrasiveness in the clinical literature, and these are described next.

\subsection{Additional Abrasive Descriptions}

Levinson (1978) claimed abrasive individuals' perception of failures in different aspects in their life accounts for their abrasive personality traits and behavior. His research suggested that having an abrasive personality is a source of significant distress and malfunction for abrasive individuals, both in the workplace and in their social life. Wepman and Donovan (1984) described abrasive individuals from the perspective of psychotherapy, and they postulated them to be "difficult" with tendencies to be abrasive, irritating, aggressive, or annoying. Kets De Vries and Balazs (1996) suggested the behaviors exhibited by the abrasive individual are often a product of perceived rejection. Matthiensen and Einarsen (2007) found that people with abrasive personality traits were more likely to express aggression towards coworkers; however, they also found that victims of bullying were just as likely to express abrasive traits; therefore, abrasiveness might, at least partially, be a result of victimization. Paulhus (2014) has used the term dark personalities to describe people with a cluster of personality traits in the subclinical range who are perceived by others as socially obnoxious, insensitive, uncongenial, and/or aversive, and this cluster appears to be similar to the previous described abrasive personality disorder traits. It is interesting to note that this literature is devoid of evidence for genetic bases for abrasive personality disorder traits as there is virtually no complex human behavior without some genetic basis (e.g., Turkheimer, 2000), and personality disorders have been found to be highly heritable in both childhood, adolescence, and adulthood (Coolidge, Thede, \& Jang, 2001; Torgersen et al., 2000).

The purpose of the present study was to develop a reliable and valid measure of abrasive personality traits. As noted previously, people with abrasive traits appear to share some of these traits with other personality disorders, thus, it was hypothesized that a newly developed abrasive personality disorder traits scale, whose items were derived from the extant literature, would have good to excellent internal scale reliability, good test-retest reliability, and strong positive correlations 
with an independent measure of paranoid, borderline, obsessive-compulsive, passive-aggressive, and narcissistic personality disorder scales. It was also hypothesized that individuals who are identified as abrasive would have higher sums on the new Abrasive Personality Traits (APT) scale than those who were not. An exploratory analysis was to be performed by means of multiple regression with the dependent variable as the sum on the new scale and the independent variables as 14 personality disorder scales defined in $D S M-5, D S M-I V$-TR, and $D S M-I I I-R$.

\section{Method}

\subsection{Materials}

Abrasive Personality Traits Scale: The newly derived APT scale consisted of 33 items, which were gleaned from the personality literature about individuals with abrasive traits, e.g., Litvak, 1994; Millon \& Birket-Smith, 1998; Levinson, 1978; Wepman \& Donovan, 1984; Kets de Vries \& Balazs, 1996; Matthiensen \& Einarsen, 2007; Paulhus, 2014). Each item was rated on a Likert-type scale from $1=$ Hardly ever, 2 = Sometimes, $3=$ Frequently, to $4=$ Almost always. Items and instructions for the scale are presented in Table 1.

Coolidge Axis II Inventory: Participants were asked to complete the 250-item, significant-other form of the Coolidge Axis II Inventory (CATI; Coolidge, 2015; Coolidge, Burns, \& Mooney, 1995; Coolidge \& Merwin, 1992). The CATI assesses 10 personality disorders from $D S M-5,2$ personality disorders from the appendix of $D S M-I V$-TR (passive-aggressive and depressive), and 2 personality disorders from $D S M$ - III-TR (sadistic and self-defeating), for a total of 14 personality disorder scales. The items on the CATI are rated on a Likert-type scale from 1 = Strongly false, $2=$ More false than true, $3=$ More true than false, to $4=$ Strongly true. The 14 CATI personality disorder scales have good internal and test-retest reliability, and good concurrent validity with the Millon Clinical Multiaxial Inventory (Millon, 1987) and Beck's Personality Beliefs Questionnaire (Beck et al., 2001).

\subsection{Participants and Procedures}

The participants consisted of undergraduate students enrolled in psychology courses, who received extra credit for their participation, and the study was approved by the Institutional Review Board of the authors' university. The students were asked if they could recognize someone meeting the following description:

This person continually manages to annoy other people whether it is a new person or someone that they know. Abrasive people can get "underneath other people's skin" quickly, or manage to "honk" other people off quickly, or in some fashion or another manage to be unlikeable and disagreeable, and they will often be avoided by others in the future if other people can manage it.

Students who said they knew someone who met these characteristics were asked to complete a demographic form describing themselves and the purportedly 
Table 1. Abrasive Personality Disorder Scale. People with abrasive personalities continually manage to annoy other people whether it's a new person or someone that they know. Abrasive people can get "underneath other people's skin" quickly, or manage to "honk" other people off quickly, or in some fashion or another manage to be unlikeable and disagreeable, and they will often be avoided by others in the future if other people can manage it. How accurately does each statement represent the person you consider to have abrasive personality disorder traits? Please rate each of the items on the following scale: 1 . Hardly Ever; 2. Sometimes; 3. Frequently; 4. Almost Always.

1. This person is quick to disagree with other people's values or opinions.

2. This person manages to insult other people either intentionally or unintentionally.

3. This person doesn't seem to listen very well to anyone else while they are talking as if this person is bored or not interested in anything someone else has to say.

4. This person appears to have a strong need to dominate conversations.

5. This person seems very inflexible about rules and rights.

6. This person seems to force his or her opinions on others.

7. This person has a strong need to be right almost about everything.

8. This person reacts with anger and frustration (or has a really hard time) when people in authority tell them to do something or do something differently.

9. This person has a strong need to control other people's lives.

10. This person often feels other people haven't done something correctly.

11. This person is disrespectful or overly critical of authority figures.

12. This person is overly sensitive of criticism by others.

13. This person seems to live by the motto: "If you want something done right, you have to do it yourself."

14. This person is quick to attack or counter-attack when he or she thinks they are being insulted.

15. This person seems to live by the motto: "Me First!"

16. This person seems to think they are particularly special, and they deserve special treatment from others.

17. This person is often overly aggressive in their speech when talking to others.

18. This person often bullies others.

19. This person seems to have a need to intimidate other people, especially when he or she is in a dominating role over other people (like teacher-student, parent-child, employer-employee, etc.).

20. This person not only has to be right about everything, but he or she also views other people's opinions as wrong.

21. This person rarely if ever admits to making a mistake.

23. This person often blames other people for his or her own mistakes.

23. This person rarely takes responsibility for their own mistakes.

24. This person has a tougher time than average of being a follower.

25. This person has a tendency to break more rules than the average person.

26. This person has a tendency to modify rules to fit their own needs.

27. This person seems to use or manipulate other people.

28. This person will often end a relationship if he or she sees no more use for that person.

29. This person will unfairly use (or abuse) other people to get ahead.

30. I consider this person to be insincere, he/she does not express honest feelings towards others.

31. This person over does it when correcting other people's mistakes or behaviors.

32. This person uses hostility, rage, or anger to stay in control of other people.

33. This person appears to be nice at first, and then later shows their true colors (abrasive).

\begin{tabular}{|c|c|c|}
\hline & 2 & 3 \\
\hline 1 & 2 & 3 \\
\hline 1 & 2 & 3 \\
\hline 1 & 2 & 3 \\
\hline 1 & 2 & 3 \\
\hline 1 & 2 & 3 \\
\hline 1 & 2 & 3 \\
\hline 1 & 2 & 3 \\
\hline 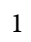 & 2 & 3 \\
\hline 1 & 2 & 3 \\
\hline 1 & 2 & 3 \\
\hline 1 & 2 & 3 \\
\hline 1 & 2 & 3 \\
\hline 1 & 2 & 3 \\
\hline 1 & 2 & 3 \\
\hline 1 & 2 & 3 \\
\hline 1 & 2 & 3 \\
\hline 1 & 2 & 3 \\
\hline 1 & 2 & 3 \\
\hline 1 & 2 & 3 \\
\hline 1 & 2 & 3 \\
\hline 1 & 2 & 3 \\
\hline 1 & 2 & 3 \\
\hline & 2 & 3 \\
\hline 1 & 2 & 3 \\
\hline 1 & 2 & 3 \\
\hline 1 & 2 & 3 \\
\hline 1 & 2 & 3 \\
\hline 1 & 2 & 3 \\
\hline 1 & 2 & 3 \\
\hline 1 & 2 & 3 \\
\hline 1 & 2 & 3 \\
\hline 1 & 2 & 3 \\
\hline
\end{tabular}


abrasive person (although the latter remained anonymous) and two questionnaires: The newly derived Abrasive Personality Disorder Traits scale and the significant-other form of the Coolidge Axis II Inventory. The students were given one week to complete the forms at school or home. Of the 84 completed forms, 30 randomly chosen participants were asked to retake the scale from one to three weeks later in order to measure its test-retest reliability. Additionally, 75 students were recruited and asked to complete the forms about a non-abrasive person as a control condition.

The 84 participating students had a mean age of 23.1 years (range $=17$ to 52 years); gender $N=7$ men and $N=77$ women. The participants' ethnicity was $71 \%$ White, $11 \%$ Asian, 9\% Hispanic/Latino, 6\% Black, and 3\% other. Their relationship to the abrasive individual was described as a "friend" by $31 \%$ of the sample, an "acquaintance" by $26 \%$, a "family member" by $17 \%$, a "romantic partner" by $1 \%$, and "other (someone who did not fit the previous four categories)" by $25 \%$. The mean age of the individuals identified as abrasive was 29.2 years (range $=17$ to 67 years); gender $N=39$ men and $N=45$ women. The abrasive individual's ethnicity was reported as $87 \%$ White, $8 \%$ Hispanic/Latino, $4 \%$ Black, and $1 \%$ Asian. Participants claimed they had known the identified abrasive individual for an average of 75 months (range $=2$ to 492 months). The 75 students in the control condition had a mean age of 23.6 years (range $=18$ to 44 years); gender $N=10$ men and $N=65$ women. Their ethnicity was $70 \%$ White, 5\% Asian, 5\% Hispanic/Latino, and 20\% mixed or other.

\section{Results}

Internal Reliability: The 33-item APT scale had excellent internal reliability, Cronbach's $\alpha=.92$ ( $N=84$ participants).

Test-Retest Reliability. There was adequate test-retest reliability. For the subset of 30 participants, $r=.77$ over a 1 to 3 -week test-retest interval. [Note: reviews of the appropriate literature revealed that using only a subset of $N=30$ was psychometrically sound].

Preliminary Construct Validity: The 75 additional undergraduate psychology students who were recruited to complete the Abrasive Personality Disorder Traits scale based on someone they knew that did not fit the initial description given to them of an abrasive individual. The second sample served as a check on the construct validity of the comparison between the purportedly abrasive and purportedly non-abrasive individuals on their sums on the new scale. The abrasive individuals' mean $(M=100.6 ; S D=15.9 ; N=84)$ was significantly higher than the non-abrasive individuals' mean $(M=53.2, S D=21.1 ; N=75), t(157)=$ $16.09, p<.0005)$ with a very strong effect size (Cohen's $d=2.54$ ).

Relationships of the Abrasive Personality Disorder scale to other personality disorder scales: As hypothesized, there were strong and significant correlations $(p<.01)$ of the Abrasive Personality Disorder scale with the Narcissistic $(r=.68)$, Paranoid $(r=.60)$, and Passive-Aggressive $(r=.50)$ CATI personality disorder 
scales. Although not hypothesized, there were also strong and significant correlations for the Sadistic $(r=.60)$ and Antisocial $(r=.55)$ personality disorder scales. See Table 2 for the complete zero-order correlation results.

Multiple Regression: The 14 CATI personality disorder scales significantly accounted for abrasiveness levels on the Abrasive Personality Disorder Traits scale, $F(14,69)=8.50, p<.0005 ; R=.80, R^{2}=.63$, adjusted $R^{2}=.56$. There were only two significant standardized $\beta$ coefficients: Narcissistic, $\beta=.55, p<.001$ as a positive predictor, and Self-Defeating, $\beta=-.29, p=.013$ as a negative predictor, both relationships were consistent with their zero-order correlations.

\section{Discussion}

The main purpose of this study was to create a measure of abrasive personality disorder traits and examine its psychometrics. The new scale had excellent internal scale reliability, acceptable test-retest reliability, and preliminary convergent validity. Of the five hypothesized zero-order correlations between the Abrasive Personality Disorder scale and the CATI personality disorder scales, three were strong and significant, and seven personality disorder scales had at least moderate or stronger correlations (e.g., $r \geq .30$ ). Although not hypothesized, the new scale also had strong positive relationships with the sadistic and antisocial personality disorder scales. Those with sadistic personality traits certainly can take advantage of others, belittle others, and delight in their suffering, which is similar to descriptions of abrasive types. Likewise, those with antisocial personality traits, as noted by Million and Birket-Smith (1998) and Schneider (1958), certainly can be aggressive, manipulative, caustic, and hostile, which also has

Table 2. Zero-Order Correlations between the Abrasive Personality Disorder scale and the 14 CATI Personality Disorder Scales.

\begin{tabular}{ccc}
\hline Personality Disorder Scale & \multicolumn{2}{c}{ Correlation } \\
\hline Narcissistic & $r=.68$ & $p<.001$ \\
Paranoid & $r=.60$ & $p<.001$ \\
Sadistic & $r=.60$ & $p<.001$ \\
Antisocial & $r=.55$ & $p<.001$ \\
Passive-Aggressive & $r=.50$ & $p<.001$ \\
Borderline & $r=.40$ & $p<.001$ \\
Schizotypal & $r=.35$ & $p=.001$ \\
Avoidant & $r=.22$ & $p<.05$ \\
Dependent & $r=.22$ & $p<.05$ \\
Histrionic & $r=.21$ & $p=.06$ \\
Schizoid & $r=.16$ & $p=.15$ \\
Depressive & $r=.13$ & $p=.23$ \\
Self-Defeating & $r=.11$ & $p=.30$ \\
Obsessive-Compulsive & $r=.10$ & $p=.36$ \\
\hline
\end{tabular}


similarities to description of abrasive people.

The results of the multiple regression supported the importance of narcissistic and self-defeating (negatively related to abrasive traits) to abrasive personality. However, due to the high multicollinearity among the 14 personality disorders as independent variables (i.e., the zero-order correlations among most all of the personality disorder scales were medium to strong), these were the only two significant standardized $\beta$ coefficients. It has been established that there is greater potential for multicollinearity when independent variables are interrelated (e.g., Nathans, Oswald, \& Nimon, 2012), thus, the ranking of beta coefficients by the weights themselves or by significance levels may be misleading. As Nathans et al. stated, "This means that there is no single 'right' way to interpret regression results, and although reliance on beta weights may feel right because it is normative practice, it provides very limited information." (p. 2). Thus, in the present study, the finding that sadistic and antisocial traits also contributed strongly to abrasiveness in the zero-order correlations may be of particular conceptual relevance to the understanding of abrasive individuals. It may also be important to note from the results of the zero-order correlations that the order and strength of the strong $(r \geq .50)$ predictors of scores on the APT scale were as follows: narcissistic, paranoid, sadistic, antisocial, and passive-aggressive.

Limitations of the present study include the sole use significant-other forms rather than self and significant-other assessment of abrasive people. Interestingly, there is empirical evidence that informant reports of personality have significantly greater internal consistency than self-reports, particularly in the assessment of personality disorder traits, so the use of significant-other assessment in the present study could be a strength rather than a complete liability (e.g., Balsis, Cooper, \& Oltmanns, 2015). Nonetheless, additional informants and self-evaluations would be valuable in future studies. The present sample was also limited to college students, relatively homogeneous in age and ethnicity, and future studies should evaluate the problem of generalization of the current results, by including diverse treatment-seeking clinical samples. It would also have been useful to explore the underlying factor structure of the new scale but the small sample size restricted such an analysis. Finally, the preliminary construct validity was inherently circular, as there would be no surprise to find that the new scale differentiated between pre-defined abrasive and non-abrasive individuals. Nonetheless, it was an important first step in the investigations of the new scale's validity.

Segal, Coolidge, and Rosowsky (2006) have already established theorized patterns for the personality disorders in later life and further research may address the pattern of abrasive personality traits as a function of growing older. We offer the tentative hypothesis that, like other high-energy personality disorder types (e.g., antisocial and borderline), those with abrasive personality features would likely show a decline in the severity of their symptoms in later life, due to the physical declines associated with aging that would make acting out more difficult in later life. Prospective and longitudinal designs which may reduce cohort effects 
should be welcomed.

In summary, the results preliminarily demonstrate that abrasiveness may constitute a reliable and valid personality symptom cluster. In addition, the traits do appear to meet the general criterion for a personality disorder in that the disorder must cause significant personal, social, and occupational/educational problems. Whether this cluster of abrasive personality traits could eventually be considered a personality disorder is certainly a matter for debate. The comorbidity of abrasive personality traits with other personality disorders should not, in and of itself, constitute an argument against the validity of a cluster of personality traits constituting a personality disorder, at least until the theoretical justifications for reducing comorbidity among personality disorders have been better elucidated. Further, there is the important issue of determining what constitutes a personality disorder and what does not. Sadistic and self-defeating personality disorders were dropped from $D S M-I V$ apparently for legal and political reasons. Depressive and passive-aggressive personality disorders were dropped from $D S M-5$ for largely unknown or specious reasons (e.g., lack of research). Perhaps, it is time for personality disorder researchers to develop a theoretically cogent definition for what properties, especially psychometric, a personality trait cluster must have (or not have) in order to qualify as a personality disorder. In the present study, although limited by a sole method of assessing disruptive personality traits, this cluster of abrasive traits was found to be internally reliable coupled with acceptable test-retest reliability and preliminary evidence for convergent validity. At the very least, further research into abrasive personality features appears warranted.

\section{References}

Balsis, S., Cooper, L. D., \& Oltmanns, T. F. (2015). Are Informant Reports of Personality More Internally Consistent Than Self Reports of Personality? Assessment, 22, 399-404. https://doi.org/10.1177/1073191114556100

Beck, A. T., Butler, A. C., Brown, G. K., Dahlsgaard, K. K., Newman, C. F., \& Beck, J. S. (2001). Dysfunctional Beliefs Discriminate Personality Disorders. Behaviour Research and Therapy, 39, 1213-1225. https://doi.org/10.1016/S0005-7967(00)00099-1

Coolidge, F. L. (2015). Coolidge Axis II Inventory: Manual. Colorado Springs, CO: Author.

Coolidge, F. L., \& Merwin, M. M. (1992). Reliability and Validity of the Coolidge Axis II Inventory: A New Inventory for the Assessment of Personality Disorders. Journal of Personality Assessment, 59, 223-238. https://doi.org/10.1207/s15327752jpa5902_1

Coolidge, F. L., \& Wynn, T. (2018). The Rise of Homo Sapiens: The Evolution of modern Thinking (2nd ed.). Oxford, UK: Oxford University Press.

Coolidge, F. L., Burns, E. M., \& Mooney, J. A. (1995). Reliability of Observer Ratings in the Assessment of Personality Disorders: A Preliminary Study. Journal of Clinical Psychology, 51, 22-28. https://doi.org/10.1002/1097-4679(199501)51:1<22::AID-JCLP2270510105>3.0.CO;2-9

Coolidge, F. L., Thede, L. L., \& Jang, K. L. (2001). Heritability of Personality Disorders in Childhood: A Preliminary Investigation. Journal of Personality Disorders, 15, 33-40. https://doi.org/10.1521/pedi.15.1.33.18645 
Kets de Vries, M., \& Balazs, K. (1996). The Human Side of Downsizing. European Management Journal, 14, 111-120. https://doi.org/10.1016/0263-2373(95)00055-0

Levinson, H. (1978). The Abrasive Personality. Harvard Business Review, 56, 86-94.

Litvak, S. B. (1994). Abrasive Personality Disorder: Definition and Diagnosis. Journal of Contemporary Psychotherapy, 24, 7-14. https://doi.org/10.1007/BF02306580

Matthiensen, S., B., \& Einarsen, S. (2007). Perpetrators and Targets of Bullying at Work: Role Stress and Individual Differences. Violence and Victims, 22, 735-753. https://doi.org/10.1891/088667007782793174

Millon, T. (1987). Millon Clinical Multiaxial Inventory-II Manual. Minneapolis, MN: National Computer Systems.

Millon, T., \& Birket-Smith, M. (1998). Psychopathy: Antisocial, Criminal and Violent Behavior. New York, NY: Guilford.

Nathans, L. L., Oswald, F. L., \& Nimon, K. (2012). Interpreting Multiple Linear Regression: A Guidebook of Variable Importance. Practical Assessment, Research \& Evaluation, 17, 1-19.

Paulhus, D. L. (2014). Toward a Taxonomy of Dark Personalities. Current Directions in Psychological Science, 23, 421-426. https://doi.org/10.1177/0963721414547737

Rusten, J., Cunningham, I. C., \& Knox, A. D. (1993). Theophrastus. Characters. Cambridge, MA: Harvard University Press.

Schneider, K. (1958). Psychopathic Personalities (9th ed., M. Hamilton, Trans.). London: Cassell.

Segal, D. L., Coolidge, F. L., \& Rosowsky, E. (2006). Personality Disorders and Older Adults. Diagnosis, Assessment, and Treatment. Hoboken, NJ: Wiley.

Torgersen, S., Lygren, S., Øien, P. A., Skre, I., Onstad, S., Edvardsen, J., Kringlen, E. et al. (2000). A Twin Study of Personality Disorders. Comprehensive psychiatry, 41, 416-425. https://doi.org/10.1053/comp.2000.16560

Turkheimer, E. (2000). Three Laws of Behavior Genetics and What They Mean. Current Directions in Psychological Science, 9, 160-164.

https://doi.org/10.1111/1467-8721.00084

Wepman, B. J., \& Donovan, M. W. (1984). Abrasiveness: Descriptive and Dynamic Issues. The Psychotherapy Patient, 1, 11-19. https://doi.org/10.1300/J358v01n01_03 